8,1897 , in the evening. She was having strong pains. Digital examination revealed only sufficient dilatation to admit point of forefinger. The waters had escaped. The presenting part could not be certainly diagnosed by vaginal touch and she was too tender and nervous for an abdominal palpation sufficiently thorough for a satisfactory diagnosis of presentation and position. The os was very rigid. After watching her for some time I noticed no progress whatever in dilatation and that she was bearing her pains very poorly. In the discharges there was not the faintest trace of blood.

The best treatment which $I$ have ever found for rigid os complicated with threatened nervous exhaustion is some form of opium in large doses. Three tablets, each containing morphia sulphate, gr. 1/4; atropin sulphate, gr. 1/150, were given hypodermatically. At $4: 30$ A.M. the pains were regular and strong and the patient had had a good rest. I found signs of a slight hemorrhage in the bed. Examination revealed a breech presenting in the sacro-left-anterior position. The presenting part had passed entirely out of the uterus and was resting under the pubic arch. The labor made slow but steady progress to a complete and safe delivery of a large male child which soon breathed and cried lustily. There was no perineal laceration. The placenta was delivered in fifteen minutes with vigorous contractions of the uterus. After delivery of the placenta I noticed something protruding from the vulva, which, with very gentle traction, separated from a slight internal attachment when it was discovered to be the os tincæ complete and entire torn off from the cervix. Not a half pint of blood was lost during the whole confinement, notwithstanding this accident. No anesthetic was given. No particular pain was complained of.

Had this complication occurred under powerful uterine action, goaded on by ergotic stimulation, it would have been less wonderful, although such an event I believe to be unheard of. But in this instance the tear took place while the patient was under the sedative and eminently relaxing influence of the morphia and atropin as above. Moreover, it happened without her being, apparently, in the slightest degree conscious of it. Her recovery was quite protracted. No hemorrhage. No odor to lochia. She had no milk for the babe, who has thrived vigorously on the bottle. She developed a phlegmasia dolens of moderate severity on one side and was very weak and feeble for three or four weeks. Her temperature would range from 100 to 103 degrees. Tablets of protonuclein and elixir digitalin seemed the most efficient medication. Milk and stimulants were used freely. She has menstruated regularly since, but more profusely than naturally. The uterus was examined a fow weeks ago and found to be granulating nicely around the site of the tear. J. S. HAMMOND, M.D.

The Humane society Deal in Fiction.

The following is a copy of a letter addressed by the Humane Society to a well-known Senator:

Washington, D. C., Feb. 19, 1898.

Dear Sir:-I desire to call your attention to the bill now before Congress, "for the further prevention of cruelty to animals in the District of Columbia," and intended for the humane regulation of the practice of vivisection.

It is not, as has been by some erroneously supposed, an "antivivisection bill," but provides only that experiments upon animals shall be performed only by properly qualifed persons; that in experiments calculated to give pain, the animal shall be rendered insensible by anesthetics; and it also provides for the appointment of four inspectors, appointed by the President of the United States, to see that these regulations are complied with and to serve without pay.

Ordinary inoculation experimente are expressly excluded from the operation of this law.

We wish to point out to you that, to the certain knowledge of the Humane Society, there are perpetrated in this country, under the name of scientific research, acts of the most revolting cruelty and barbarity; that the young of both sexes are being trained to these practices; that even in the professions of medicine and surgery, whose devotees should be of all men most humane, they are now being educated by these means to an utter indifference to the infliction of pain and the sacredness of human life; that, to our certain knowledge, this rage for experiment, engendered by its unconstrained exercise upon animals, reacts upon human subjects placed, when ill, at the mercy of persons so trained, and especially upon the sick poor in hospitals, of whose abuse by such experiments there are many known instances.

We know that cruel vivisections have been done in the District of Columbia, though to what extent we can not know, owing to the secrecy with which such experiments are surrounded. We wish, however, to provide against them for the future.

Our opponents in the District claim that they now do nothing to which the bill objects. If their conduct is already in conformity with its provisions, their opposition is absolutely without cause, and they should be glad to forward legislation to prevent the hideous abuses known to exist elsewhere from creeping into our institutions.

Indignation has been expressed that anyone should attempt to put medical and scientific men under the control of law, but we submit that there is no reason why persons of this class should be more exempt from law than merchants or bankers or other classes for whose control special laws are framed.

We call your attention to the enclosed cutting, a synopsis of the report made by Senator Gallinger of the Senate "Com. mittee of the District of Columbia," which reported the bill favorably without one aissenting voice; also to the fact that a petition in favor of this bill has been submitted to Congress of which Senator Gallinger, in presenting it, said that "probably no bill was ever presented to Congress which received the endorsement of so distinguished a list of men and women."

We beg that you will carefully consider and vote for this bill. [Signed] A. S. Pratt.

For the Humane Society.

\section{The Illinois State Board of Health.}

Springfield, Ilt., Feb. 28, 1898.

The 19th and 20th Annual Reports of this board, to be published very shortly, will contain an official register of all licensed physicians practicing in Illinois. As the reports are sent to every State in the Union, and are largely called for by professional and business men interested, I desire that the register be as correct as possible; hence would ask that you kindly accord me space in your journal to ask that every physician who wishes to have his name and address correctly reported will send the information to us on postal card at once, giving number and date of certificate.

In over 70 per cent. of cases the addresses on file in this office are those originally given when the certificates were issued, and as no additional information has been furnished this office, either by the county clerks or the physicians concerned, many physicians are reported from towns from which they moved several years ago.

$$
\text { J. A. EgaN, M.D., Sec'y. }
$$

\section{Bismuth Capsules-A New Application for the $\mathrm{X}$-Ray.}

Buffalo, N. Y., Feb. 21, 1898.

To the Editor:-In your issue of February 19, you quote from a report of Boas and Dorn, in the Deutsche Med. Woch., regarding the use of capsules of bismuth for location of lesions in the alimentary tract. As this is an important matter, in 